\title{
The Heritability of Abstract Reasoning in Caribbean Latinos with Familial Alzheimer Disease
}

\author{
Beverly Johnson $^{a}$ Vincent Santana $^{a}$ Nicole Schupf $^{a-c}$ Ming-X Tang ${ }^{d}$ \\ Yaakov Stern ${ }^{a, b}$ e $\quad$ Richard Mayeux ${ }^{a-c, e, f}$ Joseph H. Lee ${ }^{a-c}$ \\ ${ }^{\mathrm{a}}$ Taub Institute on Alzheimer's Disease and the Aging Brain, ${ }^{\mathrm{b}}$ Gertrude H. Sergievsky Center, \\ Departments of ${ }^{\mathrm{C}}$ Epidemiology and ${ }^{\mathrm{d}}$ Biostatistics, School of Public Health, and Departments of ${ }^{\mathrm{e}}$ Neurology \\ and ${ }^{\mathrm{f}}$ Psychiatry, College of Physicians and Surgeons, Columbia University, New York, N.Y., USA
}

\section{Key Words}

Heritability - Abstract reasoning • Alzheimer disease •

Cognitive reserve $\cdot$ Neuropsychology $\cdot A P O E$

\begin{abstract}
Background: Alzheimer disease (AD) is under substantial genetic influence. To better understand the genetic influence on component phenotypes of $A D$, we estimated the heritability $\left(\mathrm{h}^{2}\right)$ of abstract reasoning and examined its relation with apolipoprotein $\varepsilon 4$ (APOE- $\varepsilon 4)$. Methods: We studied abstract reasoning in 1,116 individuals from 210 Caribbean Hispanic families with late onset $A D$, using the similarities subtest scores from the Wechsler Adult Intelligence Scale. We computed $\mathrm{h}^{2}$, then performed analysis of variance to examine the effect of APOE- $\varepsilon 4$. Results: Abstract reasoning was highly heritable $\left(\mathrm{h}^{2}\right.$ unadjusted $\left.=79.9 \%\right)$. After adjusting for covariates, the $\mathrm{h}^{2}$ was reduced to $32.6 \%$, with education accounting for $40.8 \%$ of the variance. The APOE- $\varepsilon 4$ allele had no effect. Conclusion: Abstract reasoning was strongly influenced by genetic factors and education. Genes other than $A P O E$ contribute to the inheritance of abstract reasoning ability.

Copyright $\odot 2007$ S. Karger AG, Basel
\end{abstract}

(C) 2007 S. Karger AG, Basel

$1420-8008 / 07 / 0246-0411 \$ 23.50 / 0$

Fax +41613061234

E-Mail karger@karger.ch

www.karger.com
Accessible online at:

www.karger.com/dem

\section{Introduction}

Alzheimer disease (AD) is a complex neurological disease that has a significant genetic influence, with a heritability estimate of $\sim 50 \%$ [1]. To date, only 4 genes for AD have been identified and confirmed. It is clear that identification of additional genetic and environmental risk factors will elucidate the understanding of disease pathogenesis of $\mathrm{AD}$ as well as investigation of treatment and prevention. However, the difficulties of identifying susceptibility genes for common diseases such as AD are well known $[2,3]$. These diseases are likely to be influenced by multiple genes with small effect that are difficult to detect, when clinical phenotypes are analyzed. To identify additional genetic or environmental risk factors for AD, it can be highly informative to study endophenotypes - biologically associated risk factors - that are more directly influenced by the actions of the genes compared with the clinical phenotype (i.e., AD). Consequently, use of these endophenotypes (e.g., amyloid $\beta$, memory performance, visuospatial abilities) can simplify the causal pathway, can allow us to identify genetic variants and eventually help us understand the underlying mechanisms of AD. 
Decline in abstract reasoning is a valuable endophenotype for AD. According to the Diagnostic and Statistical Manual of Mental Disorders IV, AD is characterized by memory impairment with one of the following cognitive disturbances: aphasia, apraxia, agnosia or disturbance of executive functioning [4]. Executive functioning encompasses abstracting, planning, organizing and sequencing [5]. Thus, decline in abstract reasoning is a part of the diagnostic criteria for $\mathrm{AD}$, and loss of abstract reasoning ability is one of the earliest features of AD. Several studies support that abstract reasoning is an important endophenotype for AD [6-9]. For example, Jacobs et al. [8] showed that poor word finding, abstract reasoning and memory in the preclinical phase of $\mathrm{AD}$ preceded the diagnosis by 2-3 years. The Framingham study [7] reported that lower abstract reasoning and retention scores as early as 10 years prior to onset of $\mathrm{AD}$ predicted the subsequent diagnosis of AD. In the Berlin Aging Study [9], tests of attention and executive function such as abstract reasoning discriminated those who developed $\mathrm{AD}$ from those who did not. Similarly, the Paquid study [6] showed that abstract reasoning along with global cognitive functioning and visuospatial memory predicted their subsequent risk of AD. Yet, heritability of abstract reasoning has not been as extensively studied as that for memory and visuospatial abilities [10-12]. Thus, a study of the genetic influences on abstract reasoning can enhance our understanding of the genetic influences on $\mathrm{AD}[13,14]$.

We investigated the underlying genetic and environmental influences on abstract reasoning in Caribbean Latino families with familial AD. These families are an ideal population in which to define and to study further the heritability of abstract reasoning due to the high incidence of AD in Caribbean Latinos. We hypothesized that scores for abstract reasoning would decline with age, increase with educational levels but not be influenced by sex. Because intelligence has been found to be heritable, we expected abstract reasoning, measured as part of the Wechsler Adult Intelligence Scale, to be heritable $[15,16]$. To determine the heritability of abstract reasoning, we studied unaffected family members, since the heritability estimate based on both affected and unaffected members would be biased, largely reflecting the genetic influence on $\mathrm{AD}$. We then examined whether the apolipoprotein $\varepsilon 4$ (APOE- $\varepsilon 4$ ) allele explained some of the genetic variance in abstract reasoning, since APOE- $\varepsilon 4$ affects susceptibility to $\mathrm{AD}$ and abstract reasoning is a component phenotype of AD.

\section{Materials and Methods}

\section{Subjects}

A detailed description of the recruitment and evaluation for the study was previously published [17]. Briefly, recruitment for the Caribbean Latino familial AD study began in 1998 in the New York City area, the Dominican Republic and Puerto Rico. There were multiple recruitment modalities, including a random sample of Medicare recipients in Washington Heights-Inwood in New York City, and advertisement in local Latino newspapers, radio stations and postings throughout community centers. Parallel recruitment activities were also initiated in the Dominican Republic and Puerto Rico.

Following the identification of an $\mathrm{AD}$ proband, structured family interviews were carried out with family members to determine if other living relatives also had AD. To be included in the study, families had to have at least 2 living relatives affected with AD based on the National Institute of Neurological and Communicative Disorders and Stroke in Alzheimer's Disease and Related Disorders Association criteria. If a sibling was diagnosed as having $\mathrm{AD}$, all other available relatives were evaluated with the same neuropsychological, medical and neurological test battery to determine the absence or presence of $\mathrm{AD}[17,18]$. Blood was collected from all participants, and APOE genotyping was performed for all subjects.

\section{Neuropsychological Testing}

The neuropsychological battery used was developed specifically for the Spanish-speaking community. Normative data were previously collected in English and Spanish among individuals with varying educational experience as part of an epidemiologic study of dementia in Northern Manhattan [19]. This test battery was validated within this community and assessed orientation, verbal reasoning, nonverbal reasoning, naming, letter fluency, category fluency, repetition, auditory comprehension, word listing and memory, visuoperceptual skills, nonverbal memory, visuoconstructional skills and attention. Because of high prevalence of individuals with limited education in the study, we stratified subjects into 2 education groups when comparing test scores [20].

\section{Abstract Reasoning Tests}

Two tests of abstract reasoning from this battery were considered for the study: the similarities subtest of the Wechsler Adult Intelligence Scale [21] and the identities and oddities subtest of the Mattis Dementia Rating Scale [22]. The similarities test is a verbal subtest of the Wechsler Adult Intelligence Scale and asks patients to explain what a pair of words has in common, for example 'orange' and 'banana'. The identities and oddities test assesses nonverbal cognitive abilities by asking participants to determine which 2 of 3 objects are 'identical' and which is 'different'. The similarities subtest provides a spectrum of combined raw scores from 0 to 28, while the total identities and oddities combined scores range from 0 to 16 , and a low score ( $<12$ combined) serves as a cutoff for dementia. To examine the relation between abstract reasoning ability and the more extensively studied verbal and visuospatial memory, we compared the scores for the abstract reasoning tests with the scores for 2 memory tests, including the total recall score of the Selective Reminding Test [23] and the Benton Visual Retention Test (BVRT) [24]. 
Descriptive Analysis of Abstract Reasoning Scores

Descriptive statistics were carried out using SPSS version 13 [25]. We examined possible confounders, including sex, age and education levels among affected and unaffected individuals, as these were the most extensively studied confounders in evaluating the validity of these tests [20]. For continuous covariates, we used a t-test or analysis of variance to compare the 2 groups. Multiple regression analysis was used to estimate the effect of age, education and sex on abstract reasoning.

\section{Relation between Abstract Reasoning and Verbal and \\ Visuospatial Memory Scores}

To examine the strength of relations among abstract reasoning and verbal and visuospatial memory scores in unaffected individuals, we computed Pearson's correlation coefficients [25].

\section{Heritability Analysis of Abstract Reasoning}

For the heritability analysis, we used the square root of the raw score from the similarities test. Age, sex and education were adjusted in our multivariate model. However, the distribution of the scores for the identities and oddities test was highly bimodal, with affected individuals scoring extremely low and unaffected individuals scoring extremely high. Thus, we chose not to perform heritability analysis for identities and oddities because heritability analysis is sensitive to a deviation from mulitivariate normality to some extent.

We computed heritability $\left(\mathrm{h}^{2}\right)$ of abstract reasoning using SOLAR [26]. Heritability represents a proportion of additive genetic variance over the total phenotypic variance and ranges from 0 to $100 \%$, where 0 indicates no genetic influence and $100 \%$ indicates total genetic influence. We restricted the heritability analysis to unaffected individuals because the scores in the demented would primarily reflect the effect of $\mathrm{AD}$. We conducted unadjusted analysis, followed by a multivariate polygenic model, adjusting for age, education and sex. APOE- $\varepsilon 4$ was added as a covariate to determine its contribution to the heritability of abstract reasoning ability. We also compared the effect of APOE- $\varepsilon 4$ on the similarities scores with analysis of variance and used a Bonferroni correction to adjust for multiple testing. This analysis was repeated using generalized estimating equations [27] with each family treated as a cluster.

\section{Results}

\section{Demographic and Neuropsychological Data}

Data from the 1,116 individuals from the 210 families are presented in table 1 . Approximately $57 \%$ of the participants were affected with AD. Overall, the proportion of women was higher than that of men (65.9\%), and the mean age of the subjects was 70.6 years $(S D=13.1)$. The frequency of the $\varepsilon 4$ allele was higher for the affected individuals when compared with the unaffected individuals (32.1 vs. $29 \%$, respectively). In this cohort, the mean level of education was 6.6 years $(\mathrm{SD}=5.7)$, with a range of 0 to 26 years. The mean level of education for men was slightly lower than that for women (6.1 years for men vs.
Table 1. Demographic and clinical characteristics of participating subjects

\begin{tabular}{|c|c|c|}
\hline \multirow{6}{*}{$\begin{array}{l}\text { Families } \\
\text { Subjects evaluated } \\
\text { Men:women, } \% \\
\text { Mean age } \pm \text { SD, years } \\
\text { Mean education } \pm \text { SD, years } \\
\text { Demented, } \%\end{array}$} & & 210 \\
\hline & & 1,116 \\
\hline & & $34.1: 65.9$ \\
\hline & & $70.6 \pm 13.1$ \\
\hline & & $6.6 \pm 5.7$ \\
\hline & & 56.7 \\
\hline APOE allele frequency, $\%$ & Unaffected & Affected \\
\hline$\varepsilon-2$ & 4.8 & 4.5 \\
\hline$\varepsilon-3$ & 66.2 & 63.4 \\
\hline$\varepsilon-4$ & 29.0 & 32.1 \\
\hline
\end{tabular}

Table 2. Pairwise correlation coefficients of abstract reasoning and memory test scores among unaffected individuals

\begin{tabular}{lccrr}
\hline & $\begin{array}{l}\text { Similar- } \\
\text { ities }\end{array}$ & $\begin{array}{l}\text { Identities } \\
\text { and oddities }\end{array}$ & BVRT & $\begin{array}{r}\text { Total } \\
\text { recall }\end{array}$ \\
\hline Similarities & - & 0.27 & 0.52 & 0.36 \\
Identities and oddities & 463 & - & 0.27 & 0.35 \\
BVRT & 461 & 464 & - & 0.43 \\
Total recall & 463 & 465 & 465 & - \\
\hline
\end{tabular}

All correlations are significant at $\mathrm{p}<0.0001$ (2-tailed); numbers above the diagonal represent pairwise correlation coefficients, and numbers below the diagonal represent the number of subjects. Square-root transformed similarities scores were used.

6.9 years for women, $\mathrm{p}=0.036$ ). Although the direction of educational differences by sex may appear unexpected, the reason is because a greater proportion of women were under 60 years of age, and the younger individuals were better educated than the older individuals. As a result, the mean age of the women was slightly lower than that of the men in this group (70.1 vs. 71.8 years, respectively).

We then studied the relation between abstract reasoning and potential confounders, namely age, sex and education. Using the square root of the similarities score, we conducted multiple regression analysis to estimate the $\beta$ coefficients for the nongenetic factors of age, sex and education among unaffected only (table 2). Sex did not have a significant effect on similarities scores (mean for males vs. females $=2.91: 2.83 ; \mathrm{p}=0.497$ ). With each year of education, the similarities score increased by 0.41 points $(p<0.0001)$. However, we observed no effect of age on similarities scores. In addition, the similarities score and 
Table 3. Mean scores on neuropsychiatric tests

\begin{tabular}{|c|c|c|c|c|c|}
\hline & \multirow[t]{2}{*}{ Subjects } & \multicolumn{2}{|c|}{ Abstract reasoning } & \multicolumn{2}{|l|}{ Memory } \\
\hline & & similarities & identities and oddities & total recall & BVRT \\
\hline $\begin{array}{l}\text { Unaffected individuals } \\
\text { Level of education }\end{array}$ & 476 & $9.71 \pm 6.61$ & $14.07 \pm 2.22$ & $37.61 \pm 10.61$ & $6.11 \pm 2.50$ \\
\hline Above median & 297 & $12.4 \pm 6.33$ & $14.39 \pm 2.08$ & $39.98 \pm 10.80$ & $7.03 \pm 2.11$ \\
\hline Below median & 177 & $5.13 \pm 4.11$ & $13.54 \pm 2.35$ & $33.66 \pm 9.01$ & $4.53 \pm 2.34$ \\
\hline $\begin{array}{l}\text { Affected individuals } \\
\text { Level of education }\end{array}$ & 633 & $1.53 \pm 3.09$ & $6.04 \pm 6.17$ & $9.80 \pm 11.12$ & $1.52 \pm 2.23$ \\
\hline Above median & 168 & $2.67 \pm 4.50$ & $6.87 \pm 6.41$ & $10.53 \pm 11.47$ & $2.14 \pm 2.72$ \\
\hline Below median & 450 & $1.14 \pm 2.29$ & $5.66 \pm 6.07$ & $9.28 \pm 10.84$ & $1.27 \pm 1.96$ \\
\hline
\end{tabular}

All scores are significantly different between affected and unaffected with $\mathrm{p}<0.0001$, except for the difference in total recall in the affected between those with high and low education with $p=0.216$. Raw test scores were used.

the identities and oddities subtest correlated positively with the scores of verbal memory (Selective Reminding Test) and visuospatial memory (BVRT).

\section{Comparison of Cognitive Scores in Affected versus Unaffected Individuals}

As expected, the scores of the affected individuals were significantly lower than those for unaffected individuals on both the similarities subtest and the identities and oddities test, even after adjusting for education level (table 3, p < 0.0001). Among unaffected individuals, the scores for similarities and BVRT were significantly lower for those with low education, compared with those with high education. However, among affected individuals, no such relationship with education existed for total recall, similarities or the BVRT.

\section{Heritability Analysis of Abstract Reasoning}

The unadjusted estimate of the heritability of abstract reasoning among unaffected family members was $79.9 \%$. However, the heritability estimate was reduced to $32.6 \%$ when age, sex and education were included in the model (fig. 1). A substantial proportion of the phenotypic variance (40.8\%) was explained by education. Age and sex did not have a significant effect. When $A P O E-\varepsilon 4$ was included as a covariate in our multivariate polygenic model along with age, sex and education, the heritability estimate did not change $\left(h^{2}=32.6 \%\right)$.

The Effect of APOE- 84 on Abstract Reasoning Scores

One can reason that since the APOE- $\varepsilon 4$ allele increases the risk of $\mathrm{AD}$, it may influence abstract reasoning - an

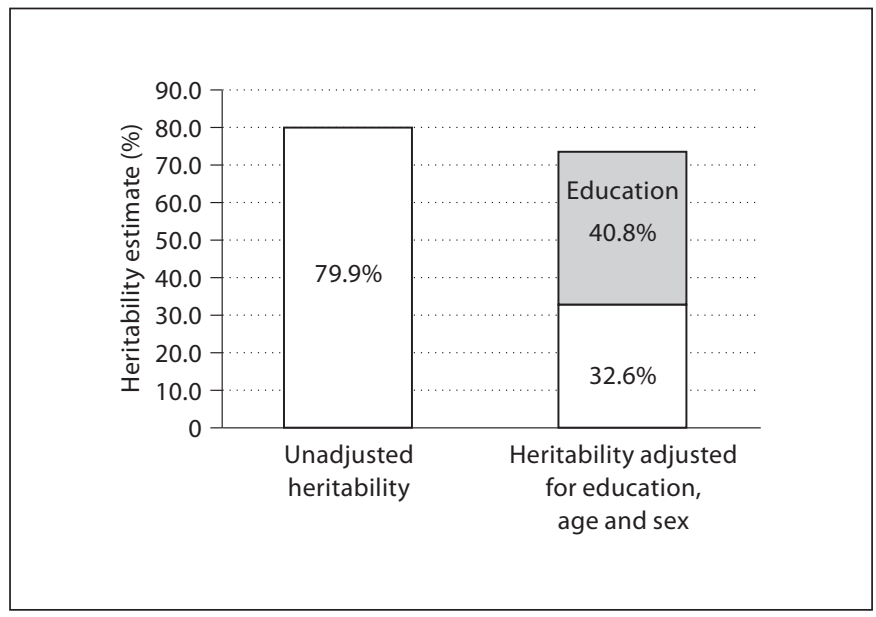

Fig. 1. Heritability of abstract reasoning. Square-root transformed similarities scores were used.

endophenotype of AD. If true, the APOE- $\varepsilon 4$ allele may influence heritability of abstract reasoning. However, we observed no difference in scores between the APOE- $\varepsilon 4$ allele carriers vs. noncarriers in the unaffected group (table 4). Among the affected individuals, similarities scores were significantly lower $(\mathrm{p}<0.001)$ in those who had at least 1 copy of an APOE- $\varepsilon 4$ allele compared with those without an APOE- $\varepsilon 4$ allele (table 4). Because this difference in affected individuals could be explained by difference in disease severity, we compared the scores among subjects within the same clinical dementia rating (CDR) scores. When stratified by their CDR scores, the APOE$\varepsilon 4$ effect was no longer significant. We repeated the anal- 
Table 4. Comparison of mean similarities scores by APOE- $\varepsilon 4$ status

\begin{tabular}{lllc}
\hline & APOE- $\varepsilon$ 4 status & $\begin{array}{l}\text { Similarities } \\
\text { mean score }\end{array}$ & p value \\
\hline \multirow{2}{*}{ Unaffected } & $\varepsilon-4$ negative & 7.90 & 0.6 \\
\multirow{3}{*}{ Affected } & $\varepsilon-4$ positive & 7.95 & \\
& $\varepsilon-4$ negative & 0.66 & $<0.001$ \\
& $\varepsilon-4$ positive & 0.34 & \\
\hline
\end{tabular}

Significance level after the Bonferroni correction; adjusted for age and education. Square-root transformed similarities scores were used.

ysis using generalized estimating equations clustering on family and including age, years of education, CDR score and APOE- $\varepsilon 4$ allele, and found that APOE- $\varepsilon 4$ had no effect on abstract reasoning ability among affected individuals.

\section{Discussion}

We report that one third of the phenotypic variance in abstract reasoning was genetically influenced, while education was equally important in explaining the variation in abstract reasoning. Moreover, the APOE- $\varepsilon 4$ allele had no effect on abstract reasoning, suggesting that there are likely to be other genes that contribute to its heritability.

This study suggests that abstract reasoning is most influenced by a combination of both heredity and educational experience. In these Caribbean Latino families, the genetic influence explained nearly one third of the variance in abstract reasoning as measured by the similarities subtest, and this estimate is comparable to the heritability estimates for general intelligence obtained from twin studies [11, 12, 28]. Moreover, education accounted for even more of the variance (40.8\%). One of the reasons for this strong influence may be due to the fact that this group of elderly individuals had low levels of education in general; thus, the impact of education may be more pronounced than in the Western populations. Age and sex had little or no effect on abstract reasoning. As expected, performance on tests of abstract reasoning and verbal and visuospatial memory scores were correlated with each other as these component phenotypes were correlated with AD.

A further examination of the effect of APOE- $\varepsilon 4$ on abstract reasoning revealed that this variant had no effect on abstract reasoning. It was posited that APOE- $\varepsilon 4$ may explain a portion of the heritability of abstract reasoning because this variant has a profound impact on AD risk, and at the same time, abstract reasoning with a modest heritability is a component phenotype of $\mathrm{AD}$. As shown in table 4 , APOE- $\varepsilon 4$ had a significant influence on abstract reasoning scores in the affected individuals but not in unaffected individuals. However, when we performed further analysis adjusting for disease severity using CDR status, we observed no effect of APOE- $\varepsilon 4$. Thus, a natural extension of this study would be to localize chromosomal regions that may harbor genes that influence abstract reasoning.

One of the motivating factors for studying abstract reasoning as an endophenotype arose from the difficulties in identifying genetic factors that influence AD. Because $\mathrm{AD}$ is a complex late onset disease, there are likely to be multiple genetic and environmental factors that contribute to $\mathrm{AD}$, and each factor is likely to have only a limited influence on the clinical phenotype. Further, these factors are likely to interact with each other, thereby making identification of these factors difficult. As a means to simplify this complexity, we chose to study abstract reasoning, which is one main component phenotype of AD. Several studies suggest that this approach can be powerful. For example, Ertekin-Taner et al. [29] localized a susceptibility gene for $\mathrm{AD}$ to a location on the long arm of chromosome 10q using amyloid $\beta$ protein level as the phenotype, and this finding was confirmed in 2 independent studies $[30,31]$ that used $\mathrm{AD}$ as the phenotype. Using memory scores as the phenotypes, Lee et al. [32,33] showed that 2 candidate genes, namely non-SMC condensin I complex, subunit D2 and glyceraldehyde-3phosphate dehydrogenase, were significantly associated with memory scores. These studies along with the present one show that endophenotypes can be used to disentangle the relation between $\mathrm{AD}$ and genetic factors.

This genetic study of abstract reasoning reveals additional insight into the role of environmental as well as genetic factors as explained by the theory of cognitive reserve. Previously, researchers have reported the disagreement between the severity of neuropathological manifestations of AD and the severity of AD [34-36]. These authors argued that individuals develop cognitive reserve in the presence of favorable environments such as high educational level, by genetic predisposition that provides protective effects against $\mathrm{AD}$, or both. Thus individuals with a greater brain reserve capacity have a higher threshold for brain insult before clinical deficit appears. The current study is consistent with the possibility that ab- 
stract reasoning is part of cognitive reserve, which may partly explain the variability in $\mathrm{AD}$ risk.

There are several limitations in this study. First, our findings may have limited generalizability, since this study utilized Caribbean Latino families with high prevalence of $\mathrm{AD}$, and the family members had low levels of education in general. Second, it is difficult to know whether the effects on abstract reasoning in late life simply reflect a lifelong pattern that may be related to overall intelligence [37]. Third, the low overall education level may skew results by truncating the range of scores. However, this would reduce the overall variability in abstract reasoning and would underrate the estimate of heritability. Fourth, the current family study is a cross-sectional study. Longitudinal follow-up, now in progress, will help to determine whether low similarities scores predict a greater likelihood of developing $\mathrm{AD}$ in other family members. Such observations can provide insight into the mechanism of how these cognitive functions contribute to the AD phenotype. Lastly, we examined abstract rea- soning with 2 neuropsychological tests: similarities, and identities and oddities. Though the results of 2 tests were available for study, only similarities could be used for the regression and heritability analyses; thus, we may not have evaluated abstract reasoning comprehensively.

The current study shows that abstract reasoning is influenced by genetic factors as well as education. Because abstract reasoning is one of the first cognitive abilities to deteriorate in $\mathrm{AD}$ and it has significant genetic influence, a further study is needed to identify genetic loci that may harbor susceptibility genes for abstract reasoning.

\section{Acknowledgments}

Funding for this project was provided by the National Institutes on Aging, National Institutes of Health R37 AG15473. B.J. was a recipient of a Medical Student Clinical Research Fellowship from the Doris Duke Charitable Foundation. In addition, support was provided by the Charles S. Robertson Gift for Research on Alzheimer's Disease from the Banbury fund.

\section{References}

1 St George-Hyslop PH, Petit A: Molecular biology and genetics of Alzheimer's disease. C R Biol 2005;328:119-130.

-2 Lander ES, Schork NJ: Genetic dissection of complex traits. Science 1994;265:20372048.

3 Terwilliger JD, Lee JH: Natural experiments in human gene mapping: the intersection of anthropological genetics and genetic epidemiology; in Crawford, $\mathrm{MH}$ (ed): Anthropological Genetics. Theory, Methods and Applications. Cambridge, University of Cambridge Press, 2006, pp 38-76.

4 American Psychiatric Association: Diagnostic and Statistical Manual of Mental Disorders (DSM-IV). Washington, American Psychiatric Association, 2000

5 Lezak MD: Neuropsychological Assessment, ed 3. New York, Oxford University Press, 1995.

-6 Amieva H, Jacqmin-Gadda H, Orgogozo JM, Le Carret N, Helmer C, Letenneur L, Barberger-Gateau P, Fabrigoule C, Dartigues JF: The 9-year cognitive decline before dementia of the Alzheimer type: a prospective population-based study. Brain 2005;128:10931101.

7 Elias MF, Beiser A, Wolf PA, Au R, White RF, D'Agostino RB: The preclinical phase of Alzheimer disease: a 22-year prospective study of the Framingham cohort. Arch Neurol 2000;57:808-813.
8 Jacobs DM, Sano M, Dooneief G, Marder K, Bell KL, Stern Y: Neuropsychological detection and characterization of preclinical Alzheimer's disease. Neurology 1995;45: 957-962.

9 Rapp MA, Reischies FM: Attention and executive control predict Alzheimer disease in late life: results from the Berlin aging study (base). Am J Geriatr Psychiatry 2005;13:134141.

10 Lee JH, Flaquer A, Stern Y, Tycko B, Mayeux $\mathrm{R}$ : Genetic influences on memory performance in familial Alzheimer disease. Neurology 2004;62:414-421.

11 McClearn GE, Johansson B, Berg S, Pedersen NL, Ahern F, Petrill SA, Plomin R: Substantial genetic influence on cognitive abilities in twins 80 or more years old. Science 1997;276: 1560-1563.

12 McGue M, Christensen K: The heritability of cognitive functioning in very old adults: evidence from Danish twins aged 75 years and older. Psychol Aging 2001;16:272-280.

13 Gottesman II, Gould TD: The endophenotype concept in psychiatry: etymology and strategic intentions. Am J Psychiatry 2003; 160:636-645.

14 Rice JP, Saccone NL, Rasmussen E: Definition of the phenotype. Adv Genet 2001;42: 69-76.

15 Bouchard TJ, McGue, M: Familial studies of intelligence: a review. Science 1981;212: 1055-1059.
16 Tambs K, Sundet JM, Magnus P: Heritability of analysis of WAIS subtests: a study of twins. Intelligence 1984;8:283-293.

17 Romas SN, Santana V, Williamson J, Ciappa A, Lee JH, Rondon HZ, Estevez P, Lantigua R, Medrano M, Torres M, Stern Y, Tycko B, Mayeux R: Familial Alzheimer disease among Caribbean Hispanics: a reexamination of its association with APOE. Arch Neurol 2002;59:87-91.

18 Mayeux R, Lee JH, Romas SN, Mayo D, Santana V, Williamson J, Ciappa A, Rondon HZ, Estevez P, Lantigua R, Medrano M, Torres M, Stern Y, Tycko B, Knowles JA: Chromosome-12 mapping of late-onset Alzheimer disease among Caribbean Hispanics. Am J Hum Genet 2002;70:237-243.

19 Jacobs DM, Sano M, Doonief G: Neuropsychological detection and characterization of preclinical Alzheimer's disease. Neurology 1995;45:957-962.

20 Stricks L, Pittman J, Jacobs D, et al: Normative data for a brief neuropsychological battery administered to English- and Spanishspeaking community-dwelling elders. J Int Neuropsychol Soc 1998;4:311-318.

21 Wechsler D: Wechsler Adult Intelligence Scale-Revised. New York, Psychological Corporation, 1981.

22 Mattis S: Geriatric Psychiatry. New York, Grune \& Stratton, 1976. 
23 Buschke H, Fuld PA: Evaluating storage, retention and retrieval in disordered memory and learning. Neurology 1974;24:10191025.

24 Benton AL: The Visual Retention Test. New York, Psychological Corporation, 1955.

25 SPSS: SPSS for Windows. Chicago, SPSS Inc, 2004.

26 Almasy L, Blangero J: Multipoint quantitative-trait linkage analysis in general pedigrees. Am J Hum Genet 1998;62:1198-1211.

27 Hardin JW, Hilbe JM: Generalized Estimating Equations. Boca Raton, Chapman \& Hall/CRC Press, 2003.

-28 Bouchard TJ Jr, McGue M: Familial studies of intelligence: a review. Science 1981;212: 1055-1059.

29 Ertekin-Taner N, Graff-Radford N, Younkin LH, Eckman C, Baker M, Adamson J, Ronald J, Blangero J, Hutton M, Younkin SG: Linkage of plasma abeta 42 to a quantitative locus on chromosome 10 in late-onset Alzheimer's disease pedigrees. Science 2000;290:23032304.
30 Bertram L, Blacker D, Mullin K, Keeney D, Jones J, Basu S, Yhu S, McInnis MG, Go RC, Vekrellis K, Selkoe DJ, Saunders AJ, Tanzi RE: Evidence for genetic linkage of Alzheimer's disease to chromosome 10q. Science 2000;290:2302-2303.

31 Myers A, Holmans P, Marshall H, Kwon J, Meyer D, Ramic D, Shears S, Booth J, DeVrieze FW, Crook R, Hamshere M, Abraham R, Tunstall N, Rice F, Carty S, Lillystone S, Kehoe P, Rudrasingham V, Jones L, Lovestone S, Perez-Tur J, Williams J, Owen MJ, Hardy J, Goate AM: Susceptibility locus for Alzheimer's disease on chromosome 10. Science 2000;290:2304-2305.

32 Lee JH, Cheng R, Rogaeva EA, Meng Y, Stern Y, Lantigua R, Medrano M, Farrer LA, St George-Hyslop P, Mayeux R: The chromosome 12p13 locus for late-onset Alzheimer disease, under review.
33 Lee JH, Lee H-S, Cheng R, Santana V, Williamson J, Lantigua R, Medrano M, Tycko B, Rogaeva E, Stern Y, St George-Hyslop P, Mayeux R: Fine mapping of $12 p$ for memory traits: a complementary approach to understand the genetics of Alzheimer disease. Int Cong Alzheimer Dis, Madrid, 2006.

34 Katzman R: Education and the prevalence of dementia and Alzheimer's disease. Neurology 1993;43:13-20.

35 Satz P: Brain reserve capacity on symptom onset after brain injury: a formulation and review of evidence for threshold theory. Neuropsychology 1993;7:273-295.

36 Stern Y: What is cognitive reserve? Theory and research application of the reserve concept. J Int Neuropsychol Soc 2002;8:448460.

37 Richards M, Sacker A: Lifetime antecedents of cognitive reserve. J Clin Exp Neuropsychol 2003;25:614-624. 